\title{
EFFICIENCY MEANS OF AQUA AEROBICS IN THE PROCESS OF TRAINING WITH WOMEN OF THE 3RD AGE CATEGORY
}

\author{
Boris RISNEAC, \\ doctor of pedagogical science, prof. USEFS, Chisinau, Moldova \\ Evelina RISNEAC, \\ doctor of pedagogical science, lector USEFS, Chisinau, Moldova
}

\begin{abstract}
Summary: Scientific and technological progress has dramatically changed and continues to change a person's life. In modern life, the role of mental labor is constantly increasing, and the physical one is decreasing.

All this lead to the fact that knowledge workers in the course of their professional activities do not receive physical exertion in the required amount.

Therefore, every year there is an increasing need to involve wide sections of the population in physical education for health promotion and prevention of various diseases.

Despite the importance of the problem raised in the work, there are a number of unresolved issues related to the study of the impact of recreational training and their program for women of mature age (55-70 years). It is internationally recognized that physical education is the primary means of maintaining and promoting the health and prevention of various diseases (cardiovascular, osteoporosis, etc.) and bad habits.

Currently, the search is relevant, as new forms of motor activity, and their availability for middle and older age groups of the population. Water aerobics is especially popular among various forms of fitness training. Their positive influence is due to the characteristic features of aqua aerobics only:

- performing movements in a horizontal position, which facilitates the load;

- unloading of the spine and improving posture;

- hydromassage of the skin, which improves the vegetative functions, reflex stimulation of the heart, peripheral blood circulation;

- a positive effect on the nervous system;

- improving the function of the respiratory system;

- tempering influence.
\end{abstract}

In connection with the foregoing, aqua aerobics is also used as a therapeutic agent for such diseases as hypertension (I-II degree), coronary heart disease, pathology of the musculoskeletal system.

Thus, the relevance of the topic of this study is due not only to the need to improve the general health of women of mature age, but also to treat various diseases and restore vitally important functions of the female body.

The object of research of this work is the process of recovery of women 55-70 years of aqua aerobics.

The subject of the research is the technique of introducing aqua aerobics in the process of improving the health of women in the 3rd age category.

The purpose of this scientific work is aimed at analyzing the influence of aqua aerobics on the process of recovery and restoration of the vital functions of the female body of the 3rd age category.

To accomplish the task we:

1. Perform theoretical analysis of the method of introducing aqua aerobics to improve the health of women in mature categories.

2. Develop and substantiate the method of application of aqua aerobics in the teaching and pedagogical process with women of the 3rd age category. The object of research of this work is the process of recovery of women 55-70 years of aqua aerobics.

To solve the tasks, a technological algorithm for designing water aerobics classes was developed, which can be presented as a list of operations implemented in a strict logical sequence. The developed algorithm includes five stages:

Stage I - pedagogical observations that were directed (built) on comprehensive pedagogical and biomedical diagnostics. The set of operations and procedures included in it made it possible to identify targets for aqua aerobic classes, to assess the level of physical condition-health, functional status and physical fitness;

Stage II - pre-designed ondein which it was provided for the identification of guidelines for building a draft system of aqua aerobics;

Stage III - consists in conducting a pedagogical experiment, where models of aqua aerobics were tested and implemented, the contents of which included the selection of tools, methods, methods, load and rest parameters ensuring the achievement of the planned results; 
Stage IV - consists in the implementation of a system of occupations during which actual indices of physical condition of students were taken into account, thereby ensuring the successful implementation of the planned tasks.

$\mathrm{V}$-stage - control and correction within the framework of which the effectiveness of the developed system of training was assessed, while indicators of health level, functional condition, physical fitness and improvement of physical parameters were determined.

In the process of conducting the study, the following methods were used: analysis of literary sources, questionnaires, pedagogical observations, the method of control tests, the method of mathematical statistics.

The study involved 20 women aged 55-70 years. The study participants did not have experience in aqua aerobics. Before starting the experimental study, all subjects underwent a medical examination, as well as control tests were carried out on previously developed tests.

The pedagogical experiment was carried out for 6 months with 3 lessons per week micro cycle. Each session lasted 70 minutes, 15 minutes on land in group composition and 55 minutes in the swimming pool according to the developed program for aqua aerobics.

In the course of the pedagogical experiment it was necessary to determine the extent to which the motor abilities and psychomotor states manifested as a result of the introduction of aqua aerobics to the healing process of the motor apparatus and the functional state of the subjects of the experimental group.

A deterministic analysis of the initial and final indices obtained and processed, indirectly characterizing the level of influence of the used funds on the total motor experience of women of the 3rd age category of the experimental group, was introduced into the procedure for determining the formation of appropriate motor manifestations.

Analysis of the dynamics of the level of morphofunctional parameters of women allowed us to determine the effectiveness of the use of aqua aerobics in comparison with the use of other means of physical education, including swimming in the training process. The results of this study are presented in Table 1

Table number 1. Dynamics of morpho-functional indicators of women in the experimental group obtained during the study. (i-initial, f-final)

\begin{tabular}{|l|c|c|c|c|}
\hline Indicators & Data & Initial & Final & $\begin{array}{c}\text { Significance of } \\
\text { Differences }\end{array}$ \\
\hline $\begin{array}{l}\text { Waist } \\
\text { circumference (cm) }\end{array}$ & I & $75,2 \pm 3,96$ & $73,4 \pm 1,51$ & $\mathrm{P}>0,05$. \\
& $\mathrm{F}$ & $75,6 \pm 3,43$ & $72,6 \pm 2,52$ & $\mathrm{P}<0,05$. \\
\hline Hip Girth (cm) & $\mathrm{I}$ & $58,8 \pm 1,92$ & $58 \pm 1,58$ & $\mathrm{P}>0,05$. \\
& $\mathrm{F}$ & $59 \pm 1,58$ & $57,4 \pm 2,34$ & $\mathrm{P}<0,05$. \\
\hline $\begin{array}{l}\text { Visceral fat ratio } \\
\text { (waist / hip) }\end{array}$ & $\mathrm{I}$ & $0,64 \pm 0,13$ & $0,63 \pm 0,02$ & $\mathrm{P}>0,05$. \\
& $\mathrm{F}$ & $0,64 \pm 0,03$ & $0,62 \pm 2,09$ & $\mathrm{P}<0,05$. \\
\hline $\begin{array}{l}\text { Index Ruffier } \\
\text { (points) }\end{array}$ & $\mathrm{I}$ & $10,8 \pm 1,92$ & $8,4 \pm 2,07$ & $\mathrm{P}<0,05$. \\
& $\mathrm{F}$ & $10,8 \pm 1,3$ & $8,2 \pm 2,83$ & $\mathrm{P}<0,05$. \\
\hline
\end{tabular}

Improving the level of morpho-functional parameters during the pedagogical research in the experimental group was significantly for all indicators $\mathrm{P}$ $<0.05$.

Along with the improvement of the parameters presented above, the experimental group increased the initial indicators in terms of the Quetelet index (by $3.77 \%$; $\mathrm{P}<0.01$ ), the $\mathrm{VC}$ (by $6.60 \%$; $\mathrm{P}<0.01$ ), and the life index (by 12, 53\%; $\mathrm{P}<0.01$ ), heart rate at rest (by $5.07 \%$ or 4.39 beats / $\mathrm{min}$; $\mathrm{P}<0.05$ ), systolic (by $4.68 \%$ or $6.84 \mathrm{~mm}$ of mercury). Art. $\mathrm{P}<0.05)$ and diastolic blood pressure (by $2.89 \%$ or $2.48 \mathrm{~mm} \mathrm{Hg}$; $\mathrm{P}<0.05$ ); Shtange's samples (by $12.29 \%$ or 4.73 seconds; P <0.01), samples with squats (by $9.68 \%$ or 19.74 seconds; $\mathrm{P}$ $<0.05$ ), PWC-170 test (by $18.66 \%$ or $2.46 \mathrm{~kg} / \mathrm{min} / \mathrm{kg}$; P
$<0,01)$, the level of health by 3.90 points or $38.80 \% \mathrm{P}$ $<0.01$.

\section{Conclusions}

1. In the course of the analysis of scientific and methodological literature, conceptual ideas and basic provisions were revealed that reveal the concept, structure and characteristics of pedagogical technology, the main directions of technologization and the stages of pedagogical design in the field of physical culture and sports. However, only a few studies have been performed on the material of a wellness training and affect only certain aspects of pedagogical design. At the same time, the issues of the system of presentation of the technology 
of pedagogical design of aqua aerobics classes by persons of mature age have not yet received their thorough scientific and practical analysis.

2. A system of aqua aerobics classes with women of mature age has been developed, structural components of which are physical exercises with their inherent load and rest parameters, combined into blocks (aimed at achieving standardized indicators of physical condition and effective solution of personality-significant problems involved) aqua aerobics, micro-, meso- and macrocycle recreational exercises.

3. In the course of pedagogical research, the high efficiency of the proposed aqua-aerobic exercise system was proved in solving the problems of rehabilitation, weight loss, improving body build proportions, normalization of physical development, functional status and all the components of physical fitness of women of mature age. It is also proved that the experimental system of occupations contributes to a more pronounced increase in the indicators of psychological comfort, well-being, as well as the satisfaction of the subjects with the organization, the procedural side and the results of occupations with aqua aerobics.

\section{Bibliography}

1. Anikin VA / The influence of aqua aerobics on the development of melting movements by young women who cannot swim / / - 2007. - p.36.

2. Bulgakov N.ZH. Water aerobics. / N.ZH. Bulgakov, I.A. Vasilyeva / M .: RGAFK, 1996.-30 p.

3. Vasilyeva I.A. Content and methods of water aerobics with women of mature age: Author's abstract. dis.can.ped.nauk / I.A. Vasiliev; RGAFK, 2005.-32s.

4. Shibalkina, MG Hydro aerobics classes with women of mature age: Textbook. manual / M.G. Shibalkina. SPb .: SPbGAFK them. PF Lesgaft, 1997.-122c. 